\title{
A pilot study to evaluate the effect of increased colonic propionate on glucose homeostasis during a hypocaloric diet
}

\author{
M. Khatib ${ }^{1,2}$, E. Chambers ${ }^{1}$, D.J. Morrison ${ }^{3}$ and G. Frost ${ }^{1}$ \\ ${ }^{1}$ Section of Nutrition Research, Division of Medicine, Imperial College, London W12 0NN, UK, \\ ${ }^{2}$ Clinical Nutrition Department, Faculty of Applied Medical Science, King Abdul-Aziz University, Saudi Arabia and \\ ${ }^{3}$ Scottish Universities Environmental Research Centre (SUERC), University of Glasgow, East Kilbride, Glasgow G75 \\ $O Q F, U K$
}

Obesity is associated with both insulin resistance and $\beta$-cell dysfunction. Diets that are restricted in calories (1) and rich in dietary fibre (2) have been shown to improve glucose homeostasis and body weight. It is thought that dietary fibre elicits these effects through short chain fatty acids (SCFAs), produced by bacterial fermentation in the gut. SCFA (acetate, propionate and butyrate) stimulate the release of the incretin glucagon-like peptide-1 (GLP-1) through activation of free fatty-acids receptors 2 and 3 (FFAR2, FFAR3) found on enteroendocrine L-cells in vivo (3) and in vitro (4). Our previous research has demonstrated that dietary supplementation with inulin propionate ester (IPE), which delivers propionate to the colon, stimulated the release of GLP-1 (5) and improved $\beta$-cell function in overweight adults (6). The aim of this pilot study was to investigate the effect of IPE supplementation on insulin sensitivity and $\beta$-cell function while following a hypocaloric weight loss diet. We hypothesized that dietary supplementation with IPE can improve insulin sensitivity and $\beta$-cell function to a great extent than the control following weight loss.

Ten healthy participants (m/f (20/80); mean (SEM), age 33 (3) years; Body mass index (BMI $\left.28.9(1) \mathrm{kg} / \mathrm{m}^{2}\right)$ ) were recruited and completed 12 weeks of intervention in a randomised, controlled, parallel design. Participants received inulin control $(\mathrm{n}=5$; four females) or IPE ( $n=5$; four females). A personalised hypocaloric diet ( $20 \%$ below estimated daily energy requirements) was prescribed to each participant. Two study-visits, baseline and after the 12-week supplementation period, were conducted to assess outcome measures. On the study days, and after an overnight fast, participants attended the clinical research facility to receive a standardised breakfast. Fasting and postprandial blood samples were analysed for glucose, insulin and GLP-1 up to 240 minutes. 0-240 min and 0-60min areas under the curve (AUC) were calculated to assess changes in total and first-phase responses, respectively. Participants from both groups lost weight after 12 weeks although this was not significantly different when compared between groups ( \%weight loss $2.6(0.9)$ IPE vs. 2.9 (1.9) inulin; $\mathrm{P}=0.8$ ). There were no within- or between-group changes in glucose, insulin or GLP-1 $\mathrm{AUCO}_{-240 \mathrm{~min}}$, however, insulin $\mathrm{AUC}_{0-60 \mathrm{~min}}$ was significantly higher following IPE supplementation when compared with the inulin group $(\mathrm{P}=0.04)$. Consequently, measurement of $\beta$-cell function was improved following IPE supplementation compared with the inulin group $(\mathrm{P}=0.02)$.

\begin{tabular}{|c|c|c|c|c|c|c|c|c|c|c|c|}
\hline & \multicolumn{5}{|l|}{ IPE } & \multicolumn{5}{|c|}{ Inulin control } & \multirow{2}{*}{$\begin{array}{l}\text { BG } \\
\text { Sig. }\end{array}$} \\
\hline & BL & SE & Wk 12 & SE & Sig. & BL & SE & Wk 12 & SE & Sig. & \\
\hline Weight (kg) & $79.4^{\mathbf{a}}$ & 5.8 & $77.3^{\mathrm{a}}$ & 5.4 & $0.04^{\mathrm{a}}$ & 77.5 & 6 & 75.2 & 6 & 0.1 & 0.8 \\
\hline Glucose $\mathrm{AUC}_{0-60}(\mathrm{mmol} / \mathrm{L})$ & 5.5 & 0.2 & 5.8 & 0.3 & 0.4 & 5.2 & 0.2 & 5.7 & 0.4 & 0.3 & 0.6 \\
\hline Insulin $\mathrm{AUC}_{0-60}(\mu \mathrm{U} / \mathrm{ml})$ & $50.9^{b}$ & 8.0 & $72.3^{\mathbf{b}, \mathbf{c}}$ & 8.6 & $0.01^{\mathbf{b}}$ & 101.8 & 31.7 & $76.8^{\mathrm{c}}$ & 24.1 & 0.2 & $0.04^{\mathrm{c}}$ \\
\hline GLP-1 $\mathrm{AUC}_{0-60}(\mathrm{pmol} / \mathrm{L})$ & 48.7 & 7.2 & 57.3 & 9.6 & 0.3 & 47.9 & 4.4 & 56.5 & 6 & 0.2 & 0.9 \\
\hline$\beta-$ cell function & $9.1^{\mathrm{d}}$ & 1.3 & $12.4^{\mathrm{d}, \mathrm{e}}$ & 1.3 & $0.02^{\mathrm{d}}$ & 19.3 & 6 & $13.5^{\mathrm{e}}$ & 4.4 & 0.1 & $0.02^{\mathrm{e}}$ \\
\hline
\end{tabular}

IPE: Inulin propionate ester; BL: Baseline; SE: Standard error; Wk 12: Week 12; Sig: Significance level; BG: between groups. AUC ${ }_{0-60}$ was calculated using the trapezoidal rule. $\beta$-cell function was calculated as the ratio of insulin $\mathrm{AUC}_{0-60}$ to glucose $\mathrm{AUC}_{0-60}$

In conclusion, the pilot data suggests that supplementation effect of IPE on improves first phase insulin release and $\beta$-cell function in humans, but this appears independent of weight-loss and not through enhanced GLP-1 release. This study was completed in accordance with the Declaration of Helsinki (Clinicaltrials.gov (NCT03322514)).

1. Kahleova H, Tura A, Hill M et al. (2018) Nutrients, 10(2), 189.

2. Larson-Meyer E, Heilbronn LK, Redman LM et al. (2006) Diabetes care, 29(6), 1337-1344.

3. Psichas A, Sleeth ML, Murphy KG et al. (2015) Int J Obes 39(3), 424-9

4. Tolhurst G, Heffron H, Lam YS et al. (2012) Diabetes 61(2), 364-71

5. Chambers ES, Viardot A, Psichas A et al. (2014) Gut 64(11), 1744-54

6. Pingitore A, Chambers ES, Hill T et al. (2016) Diabetes, Obesity and Metabolism, 19, 257-265. 